This is a post-print version of the paper

"Comparison between personal and individual exposure to urban air pollutants" published in Aerosol Science and Technology, vol. 56(6), p. 671-683, 2012.

DOI: $10.1080 / 02786821003662934$ 


\section{COMPARISON BETWEEN PERSONAL AND INDIVIDUAL EXPOSURE TO URBAN AIR POLLUTANTS}

Andrea Cattaneo, ${ }^{1}$ Matteo Taronna, ${ }^{2}$ Gaetano Garramone, ${ }^{3}$ Carlo Peruzzo, ${ }^{4}$ Christian Schlitt, ${ }^{3}$ Dario Consonni $^{5}$ and Domenico M. Cavallo ${ }^{2}$

${ }^{1}$ Department of Occupational and Environmental Health, Università degli Studi di Milano and Unit of Epidemiology, Fondazione IRCCS Ca' Granda - Ospedale Maggiore Policlinico, Milan, Italy; ${ }^{2}$ Department of Chemical and Environmental Sciences, Università degli Studi dell'Insubria, Como, Italy; ${ }^{3}$ International Centre for Pesticides and Health Risk Prevention, L. Sacco Hospital, Milano, Italy; ${ }^{4}$ Occupational Health Unit, Macchi Foundation Hospital, Varese, Italy; ${ }^{5}$ Unit of Epidemiology, Fondazione IRCCS Ca’ Granda - Ospedale Maggiore Policlinico, Milan, Italy

A. Cattaneo; Dipartimento di Medicina del Lavoro, Università degli Studi di Milano; Via San Barnaba, 8; 20122, Milano, Italy; Tel: +39 02503 20147; Fax: +39 02503 20111; e-mail: andrea.cattaneo@unimi.it

M. Taronna and D.M. Cavallo; Dipartimento di Scienze Chimiche ed Ambientali; Università degli Studi dell'Insubria; Via Valleggio 11, 22100, Como, Italy;

G. Garramone and C. Schlitt; I.C.P.S. - Centro Internazionale per gli Antiparassitari e la Prevenzione Sanitaria, Azienda Ospedaliera "Ospedale Luigi Sacco" - Polo Universitario; Via G. Stephenson, 94; 20157 Milano, Italy;

C. Peruzzo; Azienda Ospedaliera "Ospedale di Circolo e Fondazione Macchi"; Viale Borri, 57; 21100, Varese, Italy 
D. Consonni; Fondazione IRCCS Ca' Granda - Ospedale Maggiore Policlinico; Via San Barnaba, 8; 20122, Milano, Italy

Proofs should be sent to A. Cattaneo

Running title: Personal vs individual exposure

\begin{abstract}
This study tested the reliability of a novel method developed for assessing the individual exposure to size-fractionated particulate matter (PM) and gaseous urban pollutants. Individual exposure was defined as the exposure constantly measured in proximity to the subject, even during transfers.

Individual exposure was measured using a mobile monitoring unit (MMU), developed to sample simultaneously some urban pollutants of interest for public health purposes. The obtained concentrations were compared with those simultaneously collected in the breathing zone, considered as the gold standard for estimating human exposure to air pollutants.

Short-time number concentrations of ultrafine, fine and coarse particles collected by MMU were characterized by a high predictivity of personal exposures $\left(\mathrm{R}^{2}=0.89\right.$; slope $0.94-1.17$ for $\left.\mathrm{PM}<10 \mu \mathrm{m}\right)$, far superior to fixed-site measurements. 5-h time-weighted averages fully explained the variability of ultrafine and fine particles $\left(\mathrm{R}^{2}>0.99\right)$.

The concentrations of gaseous pollutants measured by MMU were less correlated with those collected in the breathing zone $\left(\mathrm{R}^{2}=0.34-0.65\right)$. Nevertheless, the capability of the MMU to detect the variations of personal exposures to $\mathrm{O}_{3}$ and $\mathrm{CO}$ was better than that normally observed using fixed measurements, likely due to the placement of the MMU in the different microenvironments where subjects spent their time.
\end{abstract}


Individual exposures measured by the MMU could be of importance in toxicological and epidemiological studies on PM, with the advantage of accounting for exposure to several gaseous copollutants.

\section{INTRODUCTION}

Human exposure to air pollutants can be assessed using direct measurements, biological monitoring or estimated using indirect methods, such as models predicting exposure from fixed sampling locations (indoor, outdoor or ambient). In the field of direct measurements, personal sampling is preferable for assessing human exposure, as it is representative of the contaminant concentration in the breathing zone (Esmen and Hall 2000; Zartarian et al. 2007). In general, such a direct exposure measurement approach strictly refers to sampling within an hemisphere of $30 \mathrm{~cm}$ (12 inches) radius extending in front of a person's face (Grammer et al. 2002; Rodes and Thornburg 2005). In some rare cases (Finuncane 1998) the breathing zone definition was restricted to an hemisphere having a radius from 15 to $23 \mathrm{~cm}(6$ to 9 inches). Studies using this type of approach, however, have the disadvantage of being very time consuming and expensive. It is also unfeasible when it is necessary to determine concentrations of several co-pollutants as it can be very difficult to perform sampling in the breathing zone while wearing a lot of instruments without interfering with normal daily activities. In recent years, some research was conducted collecting personal exposure with a multiparametric approach, as air pollution is composed of a mixture of different substances with potential impact on human health, whose effects can sometimes be combined in a synergistic way. Thus, some research groups have developed methodologies to measure personal exposure to multiple airborne pollutants (Demokritou et al. 2001; Jantunen et al. 1998;

Kim et al. 2006). In order to remedy the drawbacks of measurements in the breathing zone without losing information about the impact of human activities on exposure, we chose to measure the exposure 
in proximity of subjects (within $3 \mathrm{~m}$ ), assigning the name "individual exposure" to this exposure assessment strategy.

Moreover, the exposure assessment can be conducted using data collected by fixed monitoring stations, with the advantage of relying on a very large number of data with minimal effort in terms of time, human and economic resources. This method is therefore the most suitable for studies on large populations, although inevitably affected by a series of assumptions, sometimes critical, compared to the real exposure scenario. In general, exposure assessment is based on multiple regression models using fixed monitoring station measures combined with information on activities, exposure to tobacco smoke and infiltration efficiency of particles (Chang et al. 2003; Koenig et al. 2005; Tang et al. 2007; Wu et al. 2005). Such models are characterized by a limited or moderate predictive power. The majority of the studies finding an association between the concentrations of particulate matter (PM) and gaseous airborne pollutants and adverse effects on human health were conducted according to this design. Over the past 20 years many studies have been conducted comparing concentrations of PM and gaseous pollutants measured at the personal, indoor, residential outdoor and ambient levels. In general, associations between personal (or indoor) and residential outdoor (or ambient) concentrations tend to be better in longitudinal studies (Janssen et al. 2000) than in cross-sectional studies (Oglesby et al. 2000; Ozkaynak et al. 1996). The association between personal exposure and measurements from fixed stations varies depending on different factors, such as the variation in placement of area monitoring equipment with respect to the subjects' breathing zone (Spengler et al. 1985) and the distance from point sources. In addition, the physical-chemical properties of pollutants and some micro-environmental parameters affect the spatial distribution of particles and gases in atmospheric environments, leading to a mismatch between personal levels and fixed-site concentrations. The association may also vary as a function of the sampling period, since short-time fluctuations in concentrations, which can occur in the 
proximity of some point source emissions, are undetectable when sampling was carried out on longer time scales (Alm et al. 2001).

A moderate or good correlation was reported comparing personal concentrations of PM with the corresponding indoor levels (Adgate et al. 2003; Chang et al. 2000; Ozkaynak et al. 1996; Sørensen et al. 2005). On the contrary, much weaker associations were reported between personal and outdoor concentrations (Alm et al. 2001; Sørensen et al. 2005). Urban background monitoring stations may give a good estimate of exposure to fine particles, given the high homogeneity of particles belonging to the accumulation mode on a regional scale, but they are not suitable to characterize exposures significantly influenced by individual point sources (Oglesby et al 2000). In fact, the correlation between concentrations measured in the breathing zone and environmental levels showed significant improvements from PM with an aerodynamic diameter $\left(\mathrm{d}_{\mathrm{a}}\right)<10 \mu \mathrm{m}\left(\mathrm{PM}_{10}\right)$ to that with $\mathrm{d}_{\mathrm{a}}<2.5 \mu \mathrm{m}$ (PM2.5) (Rojas-Bracho et al. 2000).

Results from some longitudinal multi-pollutant studies conducted in US cities showed that personal versus ambient correlation for gases does not indicate use of data from fixed stations as surrogates of gaseous exposure (Sarnat J et al 2001; Sarnat S et al. 2006). In some urban environments weak correlations were found between personal and ambient nitrogen dioxide $\left(\mathrm{NO}_{2}\right)$ and ozone $\left(\mathrm{O}_{3}\right)$ concentrations (Sarnat J 2005). In general, large differences were also found between personal and ambient levels of carbon monoxide (CO) (Vellopoulou and Ashmore 1998), due again to the high spatial variability of this pollutant, especially in some outdoor environments (Dor et al. 1995, Ott 1982). As a general rule, data derived from fixed monitoring stations are unable to explain adequately the personal exposure also to this pollutant (Kim et al. 2006), especially in the short period (Alm et al. 2001). A better representation of personal exposure can be reached with an accurate data collection of the activities over time (Georgoulis et al. 2002; Vellopoulou and Ashmore 1998). In this case 
microenvironmental concentrations are, as expected, better correlated with personal exposure (Chang et al. 2000; Harrison et al 2002), especially when point source emissions, such as tobacco smoke, are excluded.

Most of the studies about the comparison between $\mathrm{O}_{3}$ personal exposure indicated a limited correspondence with the concentrations measured at a fixed site, both indoors and outdoors (Geyh et al. 2000; Lee et al. 2004; Linn et al. 1996; Sarnat J et al. 2005), because fixed site measurements do not take into account the spatial variability of $\mathrm{O}_{3}$, indoor/outdoor differences (high reactivity and low infiltration rates) and emission sources related to specific activities. Predictive models based on the weighted contribution of different activities could explain $40 \%$ of the personal exposure variability, up to $76 \%$ for subjects who spend most of their time indoors (Liu et al. 1993).

The aim of this study was to compare the exposures to multiple airborne pollutants measured by a novel Mobile Monitoring Unit (MMU), suitable for being transported by subjects throughout all their displacements, to those simultaneously measured using a typical personal sampling technique. The main innovative contribution of this study to the field of exposure assessment to PM and gaseous pollutants is the comparison, not previously investigated, of concentrations measured in the breathing zone and exposures simultaneously and continuously collected in proximity to the subject (within $3 \mathrm{~m}$ ) while he was moving across different urban microenvironments. As previously reported, we propose to call this exposure assessment strategy "individual exposure". Results can be useful for re-evaluating spurious personal exposures, or rather exposures obtained from measurements which were not strictly collected in the breathing zone (Koistinen et al. 1999; Chan et al. 2004; Vallejo et al. 2006; Liu et al. 2007), and for designing future studies on human exposure taking also into account the spatial variability of pollutants at small scale. 


\section{EXPERIMENTAL}

\section{Sampling methods}

\section{Individual exposure}

Individual exposure was measured using the MMU. This device was developed to sample various urban pollutants of interest for public health purposes. The MMU (Figure 1) consists of selective airmonitoring devices packed in a soundproof aluminium case with outer dimensions (HxWxP) $90 \times 45 \times 31 \mathrm{~cm}$ and weight $25 \mathrm{~kg}$ (ready-to-operate). Air samples are drawn at top-level of the unit (approximately $90 \mathrm{~cm}$ from the ground), except for $\mathrm{O}_{3}$ and $\mathrm{CO}$ monitors, that were fastened on the outer wall of the MMU, with air probes $80 \mathrm{~cm}$ from the ground. The sampling unit is provided with an impinger system in order to reduce isopropyl alcohol emissions, a top covering to protect sampling probes and damped wheels to avoid data loss.

Figure 1. Opened MMU, showing the internal location of instruments

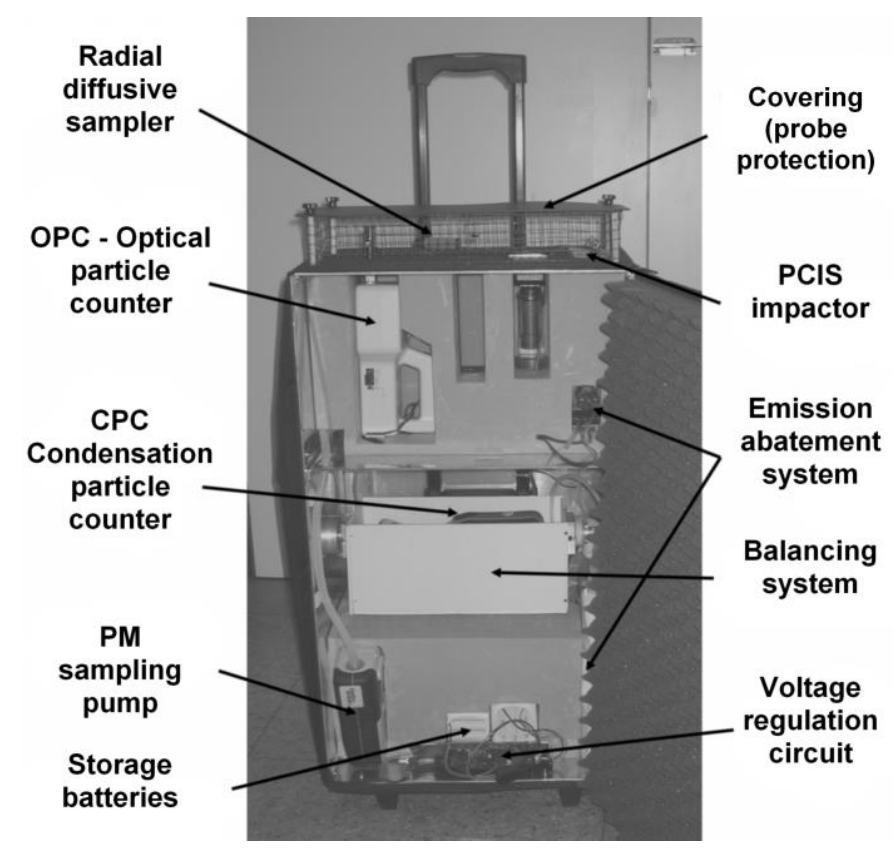


The MMU is a self-contained sampling unit capable of continuous data collection using instruments equipped with data loggers. Use of a secondary Li-ion rechargeable power supply with customized voltage regulation extends the sampling duration to $24 \mathrm{~h}$. The MMU can be moved around when staying indoors. Assistance could be needed for outdoor transfers, such as moving by car, as the unit weighs approximately $25 \mathrm{~kg}$. This makes the unit only marginally suitable for weaker subjects.

This study has been carried out simultaneously measuring personal exposure by sampling in the breathing zone and individual exposure by means of the MMU, with the purpose of comparing the results and evaluating the adequacy of individual exposure as a surrogate of personal sampling. The individual exposure was measured by carrying the MMU along every transfer performed by two trained volunteers.

\section{Personal exposure}

The personal measurements were performed in the breathing zone, placing the same monitoring instruments used for collecting individual exposures in packs strapped to the volunteers' thorax, ensuring a maximum distance of $30 \mathrm{~cm}$ between sampling probes and the nasal cavities (Figure 2).

Figure 2. Experimental setup for the measurement of personal exposure to $\mathrm{FP}, \mathrm{CP}$ and $\mathrm{O}_{3}$

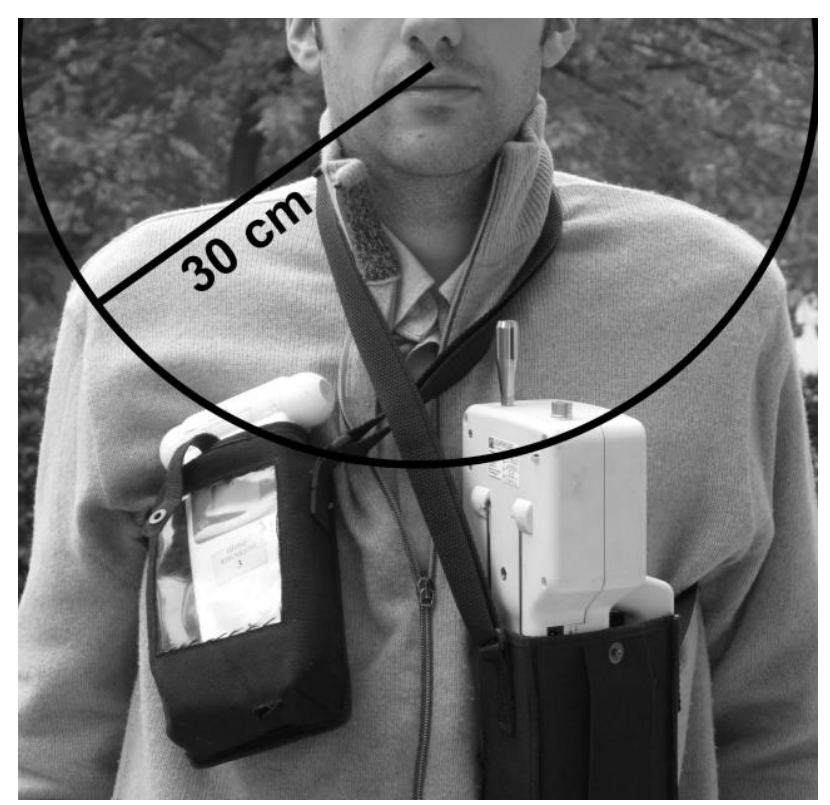




\section{Instrumental}

Ultrafine (UFP), fine (FP) and coarse particle (CP) number concentrations were continuously measured by active sampling using two portable light-scattering analyzers: a TSI P-Trak 8525 Ultrafine Particle Counter (UPC) and a Lighthouse Handheld 3016 Optical Particle Counter (OPC).

Following a worst-case scenario approach, the research was conducted only by instruments capable of data collection with high sampling frequency $(<60 \mathrm{~s})$, as it was already established that the correlation among different measurements of exposure to the same pollutant increases with increasing averaging time (Alm et al. 2001). So, the analysis of short-time data is expected to be the best approach for the identification of differences between personal and individual exposures. For this reason time-integrated sampling instruments for PM and gases included in the MMU, such as impactors and diffusive samplers (Figure 1), were not tested in this study.

The UPC was able to detect the number of particles $>0.02 \mu \mathrm{m}$, while OPC was used to measure the number of particles $>0.3 \mu \mathrm{m}$, sorted into six dimensional classes $(0.3-0.5 ; 0.5-1.0 ; 1.0-2.5 ; 2.5-5.0 ; 5.0$ $10 ;>10 \mu \mathrm{m})$. MMU was provided with a balancing system in order to maintain the horizontal position of UPC during sampling avoiding data loss.

CO concentrations were continuously collected and analyzed by passive electrochemical sensors (Langan CO measurers T15v). The zeroing and calibrating procedures of these instruments were carried out in glove bags at $20^{\circ} \mathrm{C}$ using a climatic cabinet and certified standard gas mixtures containing $<0.5 p p m$ and 10.3 ppm of $\mathrm{CO}$ in air.

$\mathrm{O}_{3}$ concentrations were acquired by portable analyzers (Aeroqual Series 500) which make use of a semiconductive sensor specific for detecting low $\mathrm{O}_{3}$ levels $(0-0.5 \mathrm{ppm})$.

All pollutants were collected with 30-s sampling intervals, except for $\mathrm{O}_{3}$ measurements, which were recorded with 1-min time resolution. 


\section{Study design}

In this study, each pollutant was sampled according to an established protocol to provide for concurrent monitoring of personal and individual exposures with the same instrumentation over 5 consecutive working days. The sampling sessions were carried out in April (UFP and CO) and October (FP, CP and $\mathrm{O}_{3}$ ), between 9.00 $\mathrm{AM}$ and 12.00 $\mathrm{AM}$ and between 2.00 PM and 4.00 PM, following a standardized route, including measurements in different places of the metropolitan area of Milan. The goal was to select locations likely to have pollutant concentrations in the ranges normally occurring in urban environments. The sampling strategy involved data collection whilst walking on major and minor streets (60 min), travelling by bus (30 $\mathrm{min}$ ) and riding trains or subways (90 $\mathrm{min})$. The protocol also included measurements in a park (60 $\mathrm{min})$ and in an office microenvironment (60min).

Before and after the sampling sessions, all pairs of instruments were subject to laboratory intercomparison tests. Pairs of instruments were exposed to specific pollutant sources (cigarette smoking for UFP, FP and $\mathrm{CO}$ and an ionizing unit for $\mathrm{O}_{3}$ ) to reproduce the studied concentration ranges. The aim was to control precision, quantifying possible systematic instrumental errors. This allowed for development of factors for a posteriori correction of data, essential to quantify the differences between personal and individual measurements minimizing the effect of instrumental errors. Accuracy of measurements and instruments was beyond the aim of this study.

Regression analyses and Bland-Altman plots (Altman and Bland 1983; Bland and Altman 1986) were carried out using time-paired data considering personal concentrations as a reference standard to assess human exposure to specified air toxicants. Bland-Altman plots are used for the comparison of two methods of measurements mainly in medical research, but they have the advantage to make easier the assessment of the magnitude of disagreement, the evaluation of error trends and the potential error in single measurements. 


\section{RESULTS}

A linear regression analysis based on the whole set of paired data was performed on UFP, FP, CP, CO and $\mathrm{O}_{3} 30$-s data and 5-h time-weighted averages (TWA) (Table 1).

Table 1. Linear regression parameters calculated for short (30-60 s) and long (5-h TWA) time periods, using personal exposures as independent variables (x-axis) and individual exposures in y-axis

\begin{tabular}{|c|c|c|c|c|c|c|c|}
\hline \multirow[t]{2}{*}{ Pollutant } & \multicolumn{4}{|c|}{ Short-time data } & \multicolumn{3}{|r|}{ 5-h TWA } \\
\hline & $\mathrm{N}$ & $\mathrm{R}^{2}$ & Slope & Intercept & $\mathrm{N}$ & $\mathrm{R}^{2}$ & Slope Intercept \\
\hline UFP: $>0.02 \mu \mathrm{m}\left(\mathrm{pt} / \mathrm{cm}^{3}\right)$ & 4263 & 0.935 & 1.042 & +1810 & 5 & 0.999 & $1.065+906$ \\
\hline FP: $0.3-0.5 \mu \mathrm{m}\left(\mathrm{pt} / \mathrm{cm}^{3}\right)$ & 2894 & 0.973 & 0.944 & +16.3 & 5 & 0.991 & $0.808+27.6$ \\
\hline FP: $0.5-1.0 \mu \mathrm{m}\left(\mathrm{pt} / \mathrm{cm}^{3}\right)$ & 2894 & 0.987 & 1.057 & -0.924 & 5 & 0.999 & $1.046-0.365$ \\
\hline FP: $1.0-2.5 \mu \mathrm{m}\left(\mathrm{pt} / \mathrm{cm}^{3}\right)$ & 2892 & 0.897 & 1.172 & -0.294 & 5 & 0.994 & $0.830+0.927$ \\
\hline $\mathrm{CP}: 2.5-5 \mu \mathrm{m}\left(\mathrm{pt} / \mathrm{cm}^{3}\right)$ & 2894 & 0.940 & 0.971 & -0.0106 & 5 & 0.911 & $0.799+0.159$ \\
\hline $\mathrm{CP}: 5-10 \mu \mathrm{m}\left(\mathrm{pt} / \mathrm{cm}^{3}\right)$ & 2894 & 0.890 & 1.076 & -0.00118 & 5 & 0.843 & $0.905+0.0368$ \\
\hline $\mathrm{CP}:>10 \mu \mathrm{m}\left(\mathrm{pt} / \mathrm{cm}^{3}\right)$ & 2843 & 0.658 & 1.122 & +0.00960 & 5 & 0.561 & $1.157+0.00914$ \\
\hline $\mathrm{CO}(\mathrm{ppm})$ & 3472 & 0.349 & 1.256 & -0.36 & 5 & 0.566 & $1.465 \quad-0.89$ \\
\hline $\mathrm{O}_{3}(\mathrm{ppm})$ & 1081 & 0.652 & 0.531 & +0.0054 & 5 & 0.397 & $0.394+0.0063$ \\
\hline
\end{tabular}

The comparison between personal and individual exposure to PM showed a good agreement between the two sampling methods $\left(\mathrm{R}^{2}=0.89 ; 0.94<\right.$ slope $\left.<1.17\right)$ for all fractions with size up to $10 \mu \mathrm{m}$. When considering 5-h TWA data the agreement improves and individual sampling fully explain the variability of numerical concentrations of FP and UFP obtained by personal sampling $\left(\mathrm{R}^{2}>0.99\right)$, despite the small population of data available. The $\mathrm{R}^{2}$ values obtained from the $\mathrm{CP}$ regressions were lower than those for 
FP and UFP, and $\mathrm{R}^{2}$ values for $\mathrm{CP}$ decreased with increasing particle size. The strength of the correlation worsened in the case of gaseous pollutants, with $\mathrm{R}^{2}$ between 0.35 and 0.65 and slopes indicating an overestimation of personal exposures to $\mathrm{CO}$ and an underestimation of personal exposures to $\mathrm{O}_{3}$.

Personal and individual short-time measurements were also compared analysing data distributions, whose central tendency values, standard deviations and relative errors, defined as [(individual exposure - personal exposure)/ personal exposure]*100, are reported in Table 2.

Table 2. Descriptive statistical parameters of personal and individual UFP, FP, $\mathrm{CP}, \mathrm{CO}$ and $\mathrm{O}_{3}$ shorttime concentrations

\begin{tabular}{|c|c|c|c|c|}
\hline Descriptiv & atistics & Personal Exposure & Individual Exposure & Relative error (\%) \\
\hline $\mathrm{UFP}>0.02 \mu \mathrm{m}\left(\mathrm{pt} / \mathrm{cm}^{3}\right)$ & Mean & 39964 & 43477 & 18.8 \\
\hline & St. Dev. & 74501 & 80323 & 31.4 \\
\hline & Median & 14393 & 15856 & 11.3 \\
\hline FP $0.3-0.5 \mu \mathrm{m}\left(\mathrm{pt} / \mathrm{cm}^{3}\right)$ & Mean & 286.54 & 254.75 & -11.0 \\
\hline & St. Dev & 170.81 & 144.56 & 9.3 \\
\hline & Median & 294.72 & 263.45 & -8.4 \\
\hline FP $0.5-1.0 \mu \mathrm{m}\left(\mathrm{pt} / \mathrm{cm}^{3}\right)$ & Mean & 44.08 & 44.56 & -0.7 \\
\hline & St. Dev & 33.58 & 35.55 & 13.5 \\
\hline & Median & 45.83 & 45.91 & 1.0 \\
\hline FP $1.0-2.5 \mu \mathrm{m}\left(\mathrm{pt} / \mathrm{cm}^{3}\right)$ & Mean & 3.38 & 3.69 & 6.0 \\
\hline & St. Dev & 2.45 & 3.05 & 23.0 \\
\hline
\end{tabular}




\begin{tabular}{|c|c|c|c|c|}
\hline & Median & 2.78 & 2.87 & 2.9 \\
\hline \multirow[t]{3}{*}{$\mathrm{CP} 2.5-5 \mu \mathrm{m}\left(\mathrm{pt} / \mathrm{cm}^{3}\right)$} & Mean & 0.82 & 0.81 & -5.5 \\
\hline & St. Dev. & 0.77 & 0.82 & 19.8 \\
\hline & Median & 0.57 & 0.56 & -6.7 \\
\hline \multirow[t]{3}{*}{ CP 5-10 $\mu \mathrm{m}\left(\mathrm{pt} / \mathrm{cm}^{3}\right)$} & Mean & 0.17 & 0.19 & 1.5 \\
\hline & St. Dev. & 0.24 & 0.28 & 45.2 \\
\hline & Median & 0.12 & 0.12 & -2.1 \\
\hline \multirow[t]{3}{*}{$\mathrm{CP}>10 \mu \mathrm{m}\left(\mathrm{pt} / \mathrm{cm}^{3}\right)$} & Mean & 0.027 & 0.040 & 91.9 \\
\hline & St. Dev. & 0.086 & 0.120 & 253.0 \\
\hline & Median & 0.015 & 0.023 & 58.3 \\
\hline \multirow[t]{3}{*}{$\mathrm{CO}(\mathrm{ppm})$} & Mean & 3.44 & 3.70 & 11.0 \\
\hline & St. Dev. & 0.82 & 1.75 & 48.8 \\
\hline & Median & 2.30 & 2.16 & -2.9 \\
\hline \multirow[t]{3}{*}{$\mathrm{O}_{3}(\mathrm{ppm})$} & Mean & 0.013 & 0.012 & -48.6 \\
\hline & St. Dev. & 0.008 & 0.005 & 41.9 \\
\hline & Median & 0.013 & 0.012 & -55.6 \\
\hline
\end{tabular}

Individual PM concentrations showed higher data variability in comparison to personal ones, as indicated by personal and individual standard deviations of short-time data (Table 2), except for the PM 0.3-0.5 $\mu \mathrm{m}$ size fraction. This behavior is even more pronounced when considering individual CO concentrations, whose standard deviation was more than double than that relative to personal $\mathrm{CO}_{2} \mathrm{O}_{3}$ personal and individual distributions were comparable, showing the same central tendency values and a higher variability of concentrations in personal exposures than in individual measurements. 
On average, the relative errors of individual exposures against personal ones were less than $20 \%$ for UFP, FP, $\mathrm{CP}<10 \mu \mathrm{m}$ and $\mathrm{CO}$ but raised up to $49 \%$ for $\mathrm{O}_{3}$ and $92 \%$ for $\mathrm{CP}>10 \mu \mathrm{m}$ (Table 2).

Bland-Altman plots of Individual-Personal (I-P) differences versus exposure levels were depicted for all measured pollutants in Figure 3. The distance of mean line from zero represents on average the absolute difference of individual measurements from the reference values (personal exposures). The 95\% limits of agreement can be used to quantitatively compare different methods of measurement as a function of acceptable precision.

Figure 3. Bland-Altman plot of I-P differences versus mean concentrations of UFPs (A), FPs (B-D), CPs (E-G), $\mathrm{CO}(\mathrm{H})$ and $\mathrm{O}_{3}(\mathrm{I})$. Broken lines represent the observed averages whereas solid lines represent the $95 \%$ limits of agreement 

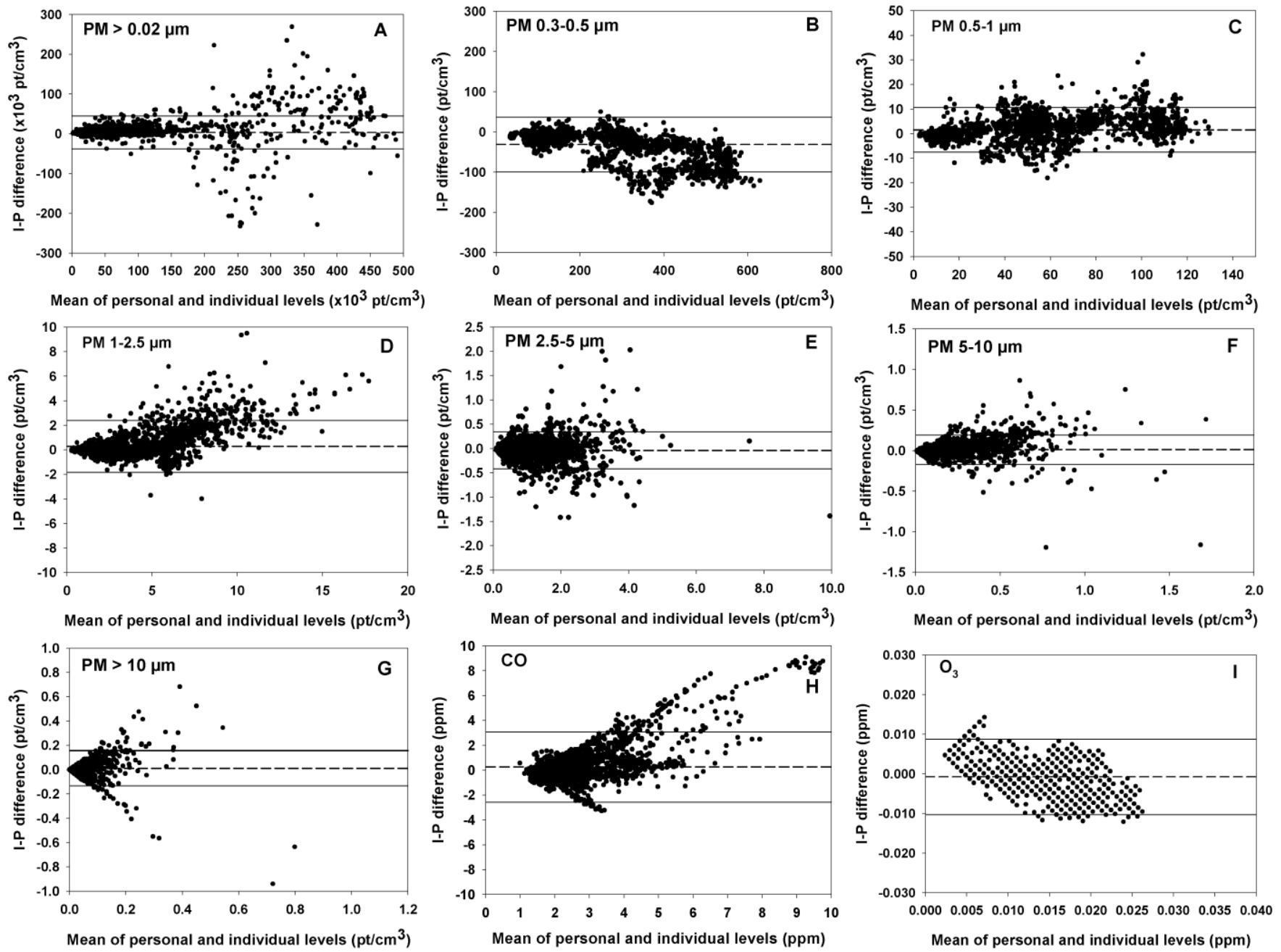

Personal and individual measurements agreed well with the exception of PM 0.3-0.5 $\mu \mathrm{m}$, PM 1-2.5 $\mu \mathrm{m}$ and $\mathrm{CO}$, which showed some error trends at high concentrations. Individual exposures to particles belonging to $0.3-0.5 \mu \mathrm{m}$ underestimated high-level exposures, leading to the mismatch between the mean line and zero (Figure 3B). On the contrary individual concentrations of PM 1-2.5 $\mu \mathrm{m}$ overestimated personal exposures at high concentrations (Figure 3D). Moreover, the differences between individual and personal exposures to particles $>10 \mu \mathrm{m}$ were very high and comparable with the concentrations measured during this study. This finding was confirmed by the width of the $95 \%$ limits of agreement, which was comparable with the majority of exposure levels (Figure 3G). The analysis of CO data showed an average value for I-P concentrations equal to $0.3 \mathrm{ppm}$, while the highest differences 
reached $10 \mathrm{ppm}$ (Figure $3 \mathrm{H}$ ). The differences between personal and individual $\mathrm{CO}$ short-time measurements, although on average distributed around zero, can therefore achieve high values in a limited number of cases. I-P concentrations of $\mathrm{CO}$ were high in comparison with the exposure concentration range and the width of the $95 \%$ limits of agreement $(-2.5 ; 3.0 \mathrm{ppm})$ showed a lack of agreement between the two methods. As sampling was performed in the Fall (October), $\mathrm{O}_{3}$ concentrations were relatively low $(<0.030 \mathrm{ppm})$. The shape of the Bland-Altman plot of $\mathrm{O}_{3}$ suggests a negative slope trend, with an underestimation of personal exposures at high concentrations, which could increase in seasons with a higher concentration range. Even in the case of $\mathrm{O}_{3}$ the width of $95 \%$ limits of agreement $(-0.010 ; 0.009 \mathrm{ppm})$ was not negligible compared to the concentrations normally occurring in ambient air (Figure 3I).

\section{DISCUSSION}

\section{PARTICULATE MATTER}

The correlation and regression parameters reported in Table 1 indicate that, if MMU is properly used, it allows a measure of TWA concentrations of UFP with an almost total predictivity of the personal ones. Moreover, the individual exposure showed an average relative error smaller than $11 \%$ compared to personal exposure, for all the other PM fractions $<10 \mu \mathrm{m}$ (Table 2). This is a very satisfactory result in the field of exposure assessment.

The individual concentrations of particles $>10 \mu \mathrm{m}$, overestimate those sampled in the breathing zone by $92 \%$ (Table 2). The same fraction presents also the highest relative differences between personal and individual measures. This phenomenon may be mainly caused by the low values of particle number concentration for particles in this size range, often close to zero. In addition, particles $>10 \mu \mathrm{m}$ are affected by a significant space variability, because their settling velocities are higher than those of FP 
(Noll and Aluko 2006). Moreover, they can be resuspended from the ground during movements and tend to remain in the lowest layers of air (Montoya and Hildemann 2005). This behavior could give a reasonable explanation to the higher $\mathrm{CP}$ concentrations measured by the $\mathrm{MMU}$, whose sampling probes are located at $80 \mathrm{~cm}$ from the floor, in comparison with personal measurements, collected at about 150 $\mathrm{cm}$ from the floor. This result contrasts with the potential dispersion of coarse dust from clothes as a result of movement (Rodes et al. 2001), which could contribute to exposures in the respiratory zone. CP play really an important role in the composition of the "personal cloud" (McBride et al. 1999; Rodes et al. 1991), but they are not usually considered the most important fraction in terms of health effects, because their incapability of penetrating the deepest parts of lungs. However, the strength of the relationship between personal and individual exposure to $\mathrm{CP}$ was greater than in previous studies, even in comparison with PM fractions with more homogeneous spatial distribution, such as $\mathrm{PM}_{2.5}$ (Kim et al. 2006; Lai et al. 2004; Meng et al. 2005). In fact, the short-time individual exposures to $\mathrm{CP}>10 \mu \mathrm{m}$, which showed the worst agreement with personal ones in the entire PM data set, explained $66 \%$ of the variability of personal concentrations and 56\% when 5-h TWA exposure data were considered (Table 1). Moreover, the Bland and Altman analysis for all the other studied PM fractions (Figure 3A-G) pointed out that the average difference I-P is very low in comparison with the concentration levels found in urban environments and micro-environments considered in this study. The mean relative errors for PM $<$ $10 \mu \mathrm{m}$ were very low $(<19 \%$ ) (Table 2$)$, thus making individual exposure measurements by MMU applicable to new fields of research, as human toxicology of size-fractionated PM.

It should be also noted that the analysis of I-P differences (Figure 3A) of UFP shows a substantial increase in absolute values and variability for concentrations above $200 \times 10^{3} \mathrm{pt} / \mathrm{cm}^{3}$. It has already been demonstrated that the agreement between different hand-held UPCs worsens considerably at high 
concentrations (Cattaneo et al. 2009). In the current study, however, this range represents about 5\% of the total sampled data.

\section{Gaseous pollutants}

The differences between personal and individual exposures to $\mathrm{CO}$, suggested also by the analysis of continuously measured data trends (Figure $3 \mathrm{H}$ ) and comparison of 90th and 95th percentiles, could be attributed to several factors, including:

- the high space variability of the pollutant, fully demonstrated in the literature especially for some outdoor environments (Dor et al. 1995; Ott 1982);

- the different distance of the two devices (breathing zone and MMU) from emission sources as vehicular traffic and indoor combustion;

- the possible influence of temperature on output signal and response time of electrochemical cells.

We can exclude a different response to $\mathrm{CO}$ variation due to loss of calibration, as the laboratory intercomparison test between the two instruments used to measure individual and personal exposures showed an excellent agreement even at the end of the sampling session (

The greater distance of the breathing zone from the most common $\mathrm{CO}$ urban point sources would explain the lower variability of personal concentrations (Table 2), as well as the lower mean values and less intense peaks (Figure $3 \mathrm{H}$ ). When considering a sampling interval of $30 \mathrm{~s}$, we found that individual measures can explain only $35 \%$ of the variability of personal exposure to $\mathrm{CO}$. The agreement improves when considering 5-h TWA data, explaining 57\% of variability, as already shown in another study on exposure to CO (Alm et al. 2001) in which an improvement in correlation between personal and ambient exposures with increasing averaging time was observed.

Although the correlation between individual and personal $\mathrm{CO}$ exposure $\left(\mathrm{R}^{2}\right)$ is lower than that obtained for PM, individual exposure to $\mathrm{CO}$ can be considered the best proxy for personal exposures, because 
other methods of exposure measurement showed lower correlations (Alm et al. 2001; Sarnat J et al. 2005). So, MMU seems to be an acceptable measurement system of CO exposure when compared with other methods reported in literature, especially when individual exposure refers to TWA data (Table 1). The lower variability of $\mathrm{O}_{3}$ data collected by the MMU (Table 2) is not necessarily attributable to real differences between individual and personal concentrations because the declared accuracy of the $\mathrm{O}_{3}$ instruments was $<0.008 \mathrm{ppm}$, which is comparable with the width of $95 \%$ limits of agreement (Figure 3I). The mean I-P value is near zero $(0.7 \mathrm{ppb})$, although there is some evidence of a trend with a negative slope for I-P versus personal concentrations (Figure 3I). Such a trend makes it impossible to exclude that the mean I-P value can vary significantly in the case of a concentration range wider than that considered in this study. This might be due to a lack of correspondence between the concentration range used for the correction of the instrumental differences $(0-70 \mathrm{ppb})$ and the range measured during the field test $(0-30 \mathrm{ppb})$. The linear regression analysis (Table 1$)$ showed quite a good association $\left(\mathrm{R}^{2}=\right.$ 0.65 ) between personal and individual $\mathrm{O}_{3}$ exposure, better than that reported for measures collected at fixed sites, where a $\mathrm{R}^{2}$ of 0.30 was obtained for indoor measurements and 0.17 for outdoor ones (Liu et al. 1993). The coefficients of determination were lower $\left(\mathrm{R}^{2}=0.40\right)$ in the case of regression on 5 -h TWA exposures to $\mathrm{O}_{3}$, owing to the strict range of values $(0.009-0.014 \mathrm{ppm}$ for individual measurements; $0.010-0.018 \mathrm{ppm}$ for personal exposures) resulting from the averaging of short-time exposures. Then, within the studied concentration ranges, the measurement of $\mathrm{O}_{3}$ concentrations by the MMU is a suitable method to assess personal short-term $\mathrm{O}_{3}$ exposures with acceptable precision. Moreover, this individual exposure measurement method should be able to detect most of the temporal and spatial variability of exposures relative to indoor and outdoor activities, which is not correctly assessable by measures at fixed position. 


\section{CONCLUSIONS AND IMPLICATIONS}

The personal/individual $(\mathrm{P} / \mathrm{I})$ ratio distributions were summarized for all the studied pollutants (Figure 4), to evaluate at the same time the correspondence and variability between personal and individual exposures considering the whole set of measurements.

Figure 4. Box plots of time-paired Personal/Individual (P/I) ratios calculated for UFP, FP, CP, CO and $\mathrm{O}_{3}$. The top, bottom, and solid line through the middle of each box correspond to the 75th percentile (top quartile), 25th percentile (bottom quartile), and 50th percentile (median), respectively. The whiskers extend from the 10th percentile (bottom decile) to the 90th percentile (top decile). Points outside whiskers represent the 5th and 95th percentiles, while and dotted lines correspond to the mean values. Solid line at $\mathrm{P} / \mathrm{I}=1$ shows the perfect agreement between personal and individual exposures

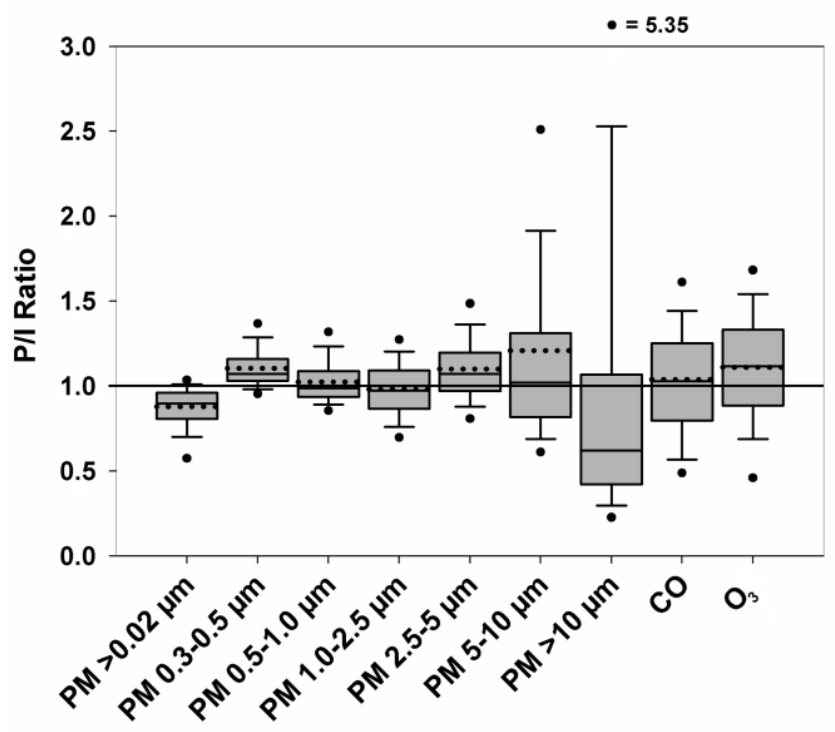

$\mathrm{P} / \mathrm{I}$ ratios present mean and median values between 0.85 and 1.15 for all pollutants, except $\mathrm{CP}>10 \mu \mathrm{m}$. $\mathrm{P} / \mathrm{I}$ ratios of $\mathrm{CP}>10 \mu \mathrm{m}$ showed greater variability and the distributions were highly skewed by extreme values (Figure 4). This is likely due to the low concentrations of $\mathrm{CP}>10 \mu \mathrm{m}$ measured in our study as well as the considerable spatial stratification of this pollutant subject to high deposition rates, coupled with the local resuspension from the ground. Furthermore, the skewness of PM distributions tended to 
increase with increasing aerodynamic diameter. However, some toxicological studies have shown the lower toxicity of CP in comparison with more reactive smaller particles (Massolo et al. 2002).

The novel sampling instrument developed for this study allowed for sampling individual exposures and comparing them with breathing zone (personal) measurements. Data from the MMU showed that over short durations, individual exposures can be highly predictive of personal exposures to particles less than $10 \mu \mathrm{m}$, better than exposure assessment methods reported previously. This is primarily due to the ability to move the MMU to the different microenvironments where the monitored subjects spent their time. In addition, this approach allowed for simultaneous collection of gaseous co-pollutants. Although individual exposures to gases were found to be moderately correlated with those concurrently collected in the breathing zone, they exhibited a better agreement with personal exposures than every other exposure assessment method reported previously. Thus, MMU can be used to detect most of the temporal and spatial variations of short-time exposures to gaseous pollutants, which are useful for accounting for their possible confounding effects in toxicological and epidemiological studies related to PM.

As already discussed in the introduction, different approaches for measuring and estimating human exposure were already deeply investigated and compared at large scale (personal vs ambient or indoor levels). But here, for the first time, a research was carried out with the aim of comparing different exposure measurement strategies at a smaller scale (personal vs individual exposures), introducing at the same time a new device (the MMU) to measure personal multi-pollutant exposures. It was demonstrated that the concentrations of some pollutants (i.e. $\mathrm{CP}$ and $\mathrm{CO}$ ) measured few meters away from a subject moving across outdoor and indoor environments, can be significantly different from those in the breathing zone. As a consequence of these results, previous studies about human exposure to gases and CP could be biased if exposure was not strictly measured in the breathing zone. On the other hand, FP 
and UFP did not show significant differences in terms of concentrations measured by personal and individual sampling. These findings suggest that future experimental studies dealing with human exposure to $\mathrm{PM}_{10}$ or its finer fractions could be carried out measuring the individual exposure without losing accuracy with respect to breathing zone (personal) measurements.

\section{ACKNOWLEDGEMENTS}

The authors greatly thank Massimo Ligorio Bisi and Annamaria Giordano for their precious help in data collection, Franco Vercelli, Salvatore Pulvirenti and Pierluigi Zambelli for the assistance in MMU development. 


\section{REFERENCES}

Adgate, J. L., Ramachandran, G., Pratt, G. C., Waller, L. A., and Sexton, K. (2003). Longitudinal variability in outdoor, indoor, and personal $\mathrm{PM}_{2.5}$ exposure in healthy non-smoking adults. Atmos. Environ. 37: 993-1002.

Alm, S., Mukala, K., Tiittanen, P., and Jantunen, M. J. (2001). Personal carbon monoxide exposures of preschool children in Helsinki, Finland: comparison to ambient air concentrations. Atmos. Environ. 35: $6259-6266$.

Altman, D. G., and Bland, J. M. (1983). Measurement in medicine: the analysis of method comparison studies. Statistician 32: 307-317.

Bland, J. M., and Altman, D. G. (1986). Statistical methods for assessing agreement between two methods of clinical measurement. Lancet 8: 307-310.

Cattaneo, A., Garramone, G., Taronna, M., Peruzzo, C., and Cavallo, D. M. (2009). Personal exposure to airborne ultrafine particles in the urban area of Milan. J. Phys. Conf. Series; doi: 10.1088/17426596/151/1/012039 [Online 13 March 2009].

Chan, C. C., Chuang, K. J., Shiao, G. M., and Lin, L. Y.(2004). Personal exposure to submicrometer particles and heart rate variability in human subjects. Environ. Health Persp. 112: 1063-1067.

Chang, L. T., Koutrakis, P., Catalano, P. J., and Suh, H. H. (2000). Hourly personal exposures to fine particles and gaseous pollutants-results from Baltimore, Maryland. J. Air Waste Manag. Assoc. 50: $1223-1235$.

Chang, L. T., Koutrakis, P., Catalano, P. J., and Suh, H. H. (2003). Assessing the importance of different exposure metrics and time-activity data to predict 24-H personal PM2.5 exposures. J. Toxicol. Environ. Health A 66: 1825-1846. 
Demokritou, P., Kavouras, I. G., Ferguson, S. T., and Koutrakis, P. (2001). Development and laboratory performance evaluation of a personal multipollutant sampler for simultaneous measurements of particulate and gaseous pollutants. Aerosol. Sci. Technol. 35: 741-752.

Dor, F., Le Moullec, Y., and Festy, B. (1995). Exposure of city residents to carbon monoxide and monocyclic aromatic hydrocarbons during commuting trips in the Paris metropolitan area. J. Air Waste Manag. Assoc. 45: 103-110.

Esmen, N. A., and Hall, T. A. (2000). Theoretical investigation of the interrelationship between stationary and personal sampling in exposure estimation. Appl. Occup. Environ. Hyg. 15: 114-119.

Finucane, E. W. (Ed). (1998). Definitions, conversions and calculations for occupational safety and health professionals. 2nd ed. CRC Press, Boca Raton FL, p. 503.

Georgoulis, L. B., Hänninen, O., Samoli, E., Katsouyanni, K., Künzli, N., Polanska, L., Bruinen de Bruin, Y., Alm, S., and Jantunen, M. (2002). Personal carbon monoxide exposure in five European cities and its determinants. Atmos. Environ. 36: 963-974.

Geyh, A. S., Xue, J., Ozkaynak, H., and Spengler, J. D. (2000). The Harvard Southern California Chronic Ozone Exposure Study: assessing ozone exposure of grade-school-age children in two Southern California communities. Environ. Health Persp. 108: 265-270.

Grammer, L. C., Harris, K. E., and Yarnold, P. R. (2002). Effect of respiratory protective devices on development of antibody and occupational asthma to an acid anhydride. Chest. 121: 1317-1322.

Harrison, R. M., Thornton, C. A., Lawrence, R. G., Mark, D., Kinnersley, R. P., and Ayres, J. G. (2002). Personal exposure monitoring of particulate matter, nitrogen dioxide, and carbon monoxide, including susceptible groups. Occup. Environ. Med. 59: 671-679. 
Janssen, N. A. H., de Hartog, J. J., Hoek, G., Brunekreef, B., Lanki, T., Timonen, K. L., and Pekkanen, J. (2000). Personal exposure to fine particulate matter in elderly subjects: Relation between personal, indoor, and outdoor concentrations. J. Air. Waste Manag. Assoc. 50: 1133-1143.

Jantunen, M. J., Hanninen, O., Katsouyanni, K., Knoppel, H., Kuenzli, N., Lebret, E., Maroni, M., Saarela, K., Sram, R., and Zmirou, D. (1998). Air pollution exposure in European cities: The "EXPOLIS" study. J. Expo. Anal. Environ. Epidemiol. 8: 495-518.

Kim, D., Sass-Kortsak, A., Purdham, J. T., Dales, R. E., and Brook, J. R. (2006). Associations between personal exposures and fixed-site ambient measurements of fine particulate matter, nitrogen dioxide, and carbon monoxide in Toronto, Canada. J. Expo. Sci. Environ. Epidemiol. 16: 172-183.

Koenig, J. Q., Mar, T. F., Allen, R. W., Jansen, K., Lumley, T., Sullivan, J. H., Trenga, C. A., Larson, T., and Liu, L. J. (2005). Pulmonary effects of indoor- and outdoor-generated particles in children with asthma. Environ. Health Persp. 113: 499-503.

Koistinen, K.J., Kousa, A., Tenhola, V., Hänninen, O., Jantunen, M.J., Oglesby, L., Kuenzli, N., and Georgoulis, L. (1999). Fine particle ( $\left.\mathrm{PM}_{2.5}\right)$ measurement methodology, quality assurance procedures, and pilot results of the EXPOLIS study. J. Air Waste Manag. Assoc. 49: 1212-20.

Lai, H. K., Kendall, M., Ferrier, H., Lindup, I., Alm, S., Haenninen, O., Jantunen, M., Mathys, P., Colvile, R., Ashmore, M.R., Cullinan, P., and Nieuwenhuijsen, M.J. (2004). Personal exposures and microenvironment concentrations of $\mathrm{PM}_{2.5}, \mathrm{VOC}, \mathrm{NO}_{2}$ and $\mathrm{CO}$ in Oxford, UK. Atmos. Environ. 38: 6399-6410.

Lee, K., Parkhurst, W. J., Xue, J. P., Ozkaynak, A. H., Neuberg, D., and Spengler, J. D. (2004). Outdoor/indoor/personal ozone exposures of children in Nashville, Tennessee. J. Air Waste Manag. Assoc. 54: 352-359. 
Linn, W. S., Shamoo, D. A., Anderson, K. R., Peng, R. C., Avol, E. L., Hackney J. D., and Gong, H. Jr. (1996). Short-term air pollution exposures and responses in Los Angeles area schoolchildren. J. Expo. Anal. Environ. Epidemiol. 6: 449-472.

Liu, L., Koutrakis, P., Suh, H., Mulik, J., and Burton, R. (1993). Use of Personal Measurements for Ozone Exposure Assessment: A Pilot Study. Environ. Health Persp. 101: 318-324.

Liu L., Ruddy T. D., Dalipaj M., Szyszkowicz M., You H. Y., Poon R., Wheeler A., and Dales R. (2007). Influence of personal exposure to particulate air pollution on cardiovascular physiology and biomarkers of inflammation and oxidative stress in subjects with diabetes. J. Occup. Environ. Med. 49: $258-265$.

Massolo, L., Müller, A., Tueros, M., Rehwagen, M., Franck, U., Ronco, A., and Herbarth, O. (2002). Assessment of mutagenicity and toxicity of different-size fractions of air particulates from La Plata, Argentina, and Leipzig, Germany. Environ. Toxicol. 17: 219-231.

McBride, S. J., Ferro, A., Ott, W., Switzer, P., and Hildemann, L. M. (1999). Investigations of the proximity effect for pollutants in the indoor environment. J. Expo. Anal. Environ. Epidemiol. 9: 602621.

Meng, Q. Y., Turpin, B. J., Korn, L., Weisel, C. P., Morandi, M., Colome, S., Zhang, J. J., Stock, T., Spektor, D., Winer, A., Zhang, L., Lee, J. H., Giovanetti, R., Cui, W., Kwon, J., Alimokhtari, S., Shendell, D., Jones, J., Farrar, C., and Maberti, S. (2005). Influence of ambient (outdoor) sources on residential indoor and personal PM2.5 concentrations. Analyses of RIOPA data. J. Expo. Anal. Environ. Epidemiol. 15: 17-28.

Montoya, L. D., and Hildemann, L. M. (2005). Size distributions and height variations of airborne particulate matter and cat allergen indoors immediately following dust-disturbing activities. J. Aerosol. Sci. 36: 735-749. 
Noll, K. E., and Aluko, O. (2006). Changes in large particle size distribution due to dry deposition processes. J. Aerosol. Sci. 37: 1797-1808.

Oglesby, L., Kunzli, N., Roosli, M., Braun-Fahrlander, C., Mathys, P., Stern, W., Jantunen, M., and Kousa, A. (2000). Validity of ambient levels of fine particles as surrogate for personal exposure to outdoor air pollution. Results of the European EXPOLIS-EAS study (Swiss Center Basel). J. Air Waste Manag. Assoc. 50: 1251-1261.

Ott, W. R. (1982). Concepts of human exposure to air pollution. Environ. Int. 7: 179-196.

Ozkaynak, H., Xue, J., Spengler, J., Wallace, L., Pellizzari, E., and Jenkins, P. (1996). Personal exposure to airborne particles and metals: results from the Particle TEAM study in Riverside, California. J. Expo. Anal. Environ. Epidemiol. 6: 57-78.

Rodes, C. E., Kamens, R. M., and Wiener, R. W. (1991). The significance and characteristics of the personal activity cloud on exposure assessment measurements for indoor contaminants. Indoor Air 2: $123-145$.

Rodes, C. E., Lawless, P. A., Evans, G. F., Sheldon, L. S., Williams, R. W., Vette, A. F., Creason, J.P., and Walsh, D. (2001). The relationships between personal PM exposures for elderly populations and indoor and outdoor concentrations for three retirement center scenarios. J. Expo. Anal. Environ. Epidemiol. 11: 103-115.

Rodes, C. E., and Thornburg, J. W. (2005). Breathing zone exposure assessment, in Aerosols Handbook: Measurement, Dosimetry, and Health Effects, L.S. Ruzer and N.H. Harley, eds., CRC Press, Boca Raton FL, 61-74.

Rojas-Bracho, L., Suh, H. H., and Koutrakis, P. (2000). Relationships among personal, indoor, and outdoor fine and coarse particle concentrations for individuals with COPD. J. Expo. Anal. Environ. Epidemiol. 10: 294-306. 
Sarnat, J. A., Brown, K. W., Schwartz, J., Coull, B. A., and Koutrakis, P. (2005). Ambient gas concentrations and personal particulate matter exposures: implications for studying the health effects of particles. Epidemiology. 16: 385-395.

Sarnat, J. A., Schwartz, J., Catalano, P. J., and Suh, H. H. (2001). Gaseous pollutants in particulate matter epidemiology: confounders or surrogates? Environ. Health Perspect. 109: 1053-1061.

Sarnat, S. E., Coull, B. A., Schwartz, J., Gold, D. R., and Suh, H. H. (2006). Factors affecting the association between ambient concentrations and personal exposures to particles and gases. Environ. Health Perspect. 114: 649-654.

Sørensen, M., Loft, S., Andersen, H. V., Raaschou-Nielsen, O., Skovgaard, L. T., Knudsen, L. E., Nielsen, I. V., and Hertel, O. (2005). Personal exposure to $\mathrm{PM}_{2.5}$, black smoke and $\mathrm{NO}_{2}$ in Copenhagen: relationship to bedroom and outdoor concentrations covering seasonal variation. J. Expo. Anal. Environ. Epidemiol. 15: 413-422.

Spengler, J. D., Treltman, R. D., Tosteson, T. D., Mage, D. T., and Soczek, M. L. (1985). Personal exposures to respirable particulates and implications for air pollution epidemiology. Environ. Sci. Technol. 19: 700-707.

Tang, C. S., Chang, L. T., Lee, H. C., and Chan, C. C. (2007). Effects of personal particulate matter on peak expiratory flow rate of asthmatic children. Sci. Total Environ. 382: 43-51.

Vallejo M., Ruiz, S., Hermosillo, A. G., Borja-Aburto, V. H., and Cardenas, M. (2006). Ambient fine particles modify heart rate variability in young healthy adults. J. Exp. Sci. Environ. Epidemiol. 16: 125130.

Vellopoulou, A. V., and Ashmore, M. R. (1998). Personal exposures to carbon monoxide in the city of Athens: I. Commuters' exposures. Environ. Int. 24: 713-720. 
Wu, C. F., Delfino, R. J., Floro, J. N., Quintana, P. J. E., Samimi, B. S., Kleinman, M. T., Allen, R. W., and Liu, L. J. (2005). Exposure assessment and modeling of particulate matter for asthmatic children using personal nephelometers. Atmos. Environ. 39: 3457-3469.

Zartarian, V.G., Ott, W.R., and Duan, N. Basic Concepts and Definitions of Exposure and Dose, in Exposure Analysis, W.R. Ott, A.C. Steinemann, L.A. Wallace, eds., CRC Press, Boca Raton, FL, 33-63. 